\title{
Alzheimer's disease-associated (hydroxy)methylomic changes in the brain and blood
}

Roy Lardenoije ${ }^{1,2+}$, Janou A. Y. Roubroeks ${ }^{1,3 \dagger}$, Ehsan Pishva ${ }^{1,3+}{ }^{\dagger}$, Markus Leber ${ }^{4}$, Holger Wagner $^{5}$, Artemis latrou ${ }^{1}$, Adam R. Smith ${ }^{3}$, Rebecca G. Smith ${ }^{3}$, Lars M. T. Eijssen 1,6, Luca Kleineidam ${ }^{4,5,7}$, Amit Kawalia ${ }^{5}$, Per Hoffmann ${ }^{8,9,10}$, Tobias Luck ${ }^{11}$, Steffi Riedel-Heller ${ }^{11}$, Frank Jessen ${ }^{7,12}$, Wolfgang Maier ${ }^{5,7}$, Michael Wagner ${ }^{5,7}$, René Hurlemann ${ }^{13}$, Gunter Kenis ${ }^{1}$, Muhammad Ali ${ }^{1,14}$, Antonio del Sol ${ }^{14,15,16,17}$, Diego Mastroeni ${ }^{1,18,19}$, Elaine Delvaux ${ }^{18,19}$,

Paul D. Coleman ${ }^{18,19}$, Jonathan Mill ${ }^{3,20}$, Bart P. F. Rutten ${ }^{1}$, Katie Lunnon ${ }^{3}$, Alfredo Ramirez ${ }^{4,5 \dagger}$ and

Daniël L. A. van den Hove $e^{1,21^{*+}}$

\begin{abstract}
Background: Late-onset Alzheimer's disease (AD) is a complex multifactorial affliction, the pathogenesis of which is thought to involve gene-environment interactions that might be captured in the epigenome. The present study investigated epigenome-wide patterns of DNA methylation (5-methylcytosine, $5 \mathrm{mC}$ ) and hydroxymethylation (5hydroxymethylcytosine, $5 \mathrm{hmC}$ ), as well as the abundance of unmodified cytosine (UC), in relation to AD.

Results: We identified epigenetic differences in AD patients $(n=45)$ as compared to age-matched controls $(n=35)$ in the middle temporal gyrus, pertaining to genomic regions close to or overlapping with genes such as OXT ($\left.3.76 \% 5 \mathrm{mC}, p_{\text {šidák }}=1.07 \mathrm{E}-06\right)$, CHRNB1 $(+1.46 \% 5 \mathrm{hmC}$, p̌sidák $=4.01 \mathrm{E}-04)$, RHBDF2 $(-3.45 \%$ UC, p̌sidák $=4.85 \mathrm{E}-06)$, and C3 $\left(-1.20 \%\right.$ UC, $\left.p_{\text {Šidák }}=1.57 \mathrm{E}-03\right)$. In parallel, in an independent cohort, we compared the blood methylome of converters to AD dementia $(n=54)$ and non-converters $(n=42)$, at a preclinical stage. DNA methylation in the same region of the OXT promoter as found in the brain was found to be associated with subsequent conversion to $\mathrm{AD}$ dementia in the blood of elderly, non-demented individuals ( $+3.43 \% 5 \mathrm{mC}$, $\left.p_{\text {šidák }}=7.14 \mathrm{E}-04\right)$.

Conclusions: The implication of genome-wide significant differential methylation of OXT, encoding oxytocin, in two independent cohorts indicates it is a promising target for future studies on early biomarkers and novel therapeutic strategies in AD.
\end{abstract}

Keywords: Alzheimer's disease, Epigenetics, DNA methylation, DNA hydroxymethylation, Brain, Middle temporal gyrus, Blood

\section{Background}

The neuropathological cascade of the world's leading cause of dementia, late-onset Alzheimer's disease (AD), is characterized by the progressive accumulation of

\footnotetext{
* Correspondence: d.vandenhove@maastrichtuniversity.nl

${ }^{\dagger}$ Roy Lardenoije, Janou A. Y. Roubroeks, Ehsan Pishva, Alfredo Ramirez and

Daniël L. A. van den Hove contributed equally to this work.

${ }^{1}$ School for Mental Health and Neuroscience (MHeNS), Department of

Psychiatry and Neuropsychology, Maastricht University, P.O. Box 616, 6200,

MD, Maastricht, the Netherlands

${ }^{21}$ Department of Psychiatry, Psychosomatics and Psychotherapy, University of

Würzburg, Würzburg, Germany

Full list of author information is available at the end of the article
}

extracellular amyloid plaques and intracellular neurofibrillary tangles, followed by neuronal cell death. The susceptibility to $\mathrm{AD}$ is determined by the complex interaction of genetic, environmental, and life-style factors, as well as epigenetic factors. Genetic research has been successful in identifying genetic variants modulating susceptibility to $\mathrm{AD}$, including the first and strongest genetic risk factor for $\mathrm{AD}$ in the $A P O E$ gene. In addition to $A P O E$, large-scale genome-wide association studies looking at $\mathrm{AD}$ have identified a number of independent common variants with a small-to-modest effect size [1]. Besides genetics, recent studies have suggested an

(c) The Author(s). 2019 Open Access This article is distributed under the terms of the Creative Commons Attribution 4.0 International License (http://creativecommons.org/licenses/by/4.0/), which permits unrestricted use, distribution, and 
important role for epigenetic mechanisms in the etiology of $\mathrm{AD}$ [2], with reports of both global and gene-specific alterations in epigenetic modifications [3-6].

Several types of epigenetic DNA modifications have been described, including DNA methylation (5-methylcytosine, $5 \mathrm{mC}$ ) and DNA hydroxymethylation (5-hydroxymethylcytosine, $5 \mathrm{hmC}$ ). While the best studied epigenetic DNA modification, $5 \mathrm{mC}$, plays an important gene regulatory role in most tissues, $5 \mathrm{hmC}$ seems to have a different impact on gene expression and is particularly enriched in the brain $[7,8]$, where it may play an important role in learning and memory $[9,10]$. Unfortunately, conventional bisulfite (BS) conversion, a widely used procedure when quantifying DNA methylation, does not distinguish between $5 \mathrm{mC}$ and $5 \mathrm{hmC}$. However, combining measurements from BS- and oxidative BS (oxBS)-converted DNA now allows for the quantification of both $5 \mathrm{mC}$ and $5 \mathrm{hmC}$ levels (Fig. 1).

Where genetic factors can identify persons at risk for developing $\mathrm{AD}$ from birth, epigenetic markers may offer more dynamic views on trajectories of biological change and may therefore be able to offer an improved, chronological insight into the sequence of events at different stages of AD. As brain tissue cannot be readily sampled in living humans, blood may offer an alternative. Available research on the blood DNA methylome in relation to $\mathrm{AD}$ is limited and mainly focuses on the direct comparison of $\mathrm{AD}$ cases and healthy controls [3, 11, 12]. Identifying disease-predicting biological profiles at predementia stages of AD may provide improved precision in predicting onset of dementia and give potential treatments a better timeframe to successfully impede, or even halt disease progression [13, 14].

In the present study, we explored the association between $\mathrm{AD}$ and epigenetic dysregulation by quantifying $5 \mathrm{mC}$ and $5 \mathrm{hmC}$, as well as unmodified cytosine (UC) proportions [15], at a single-site resolution in middle temporal gyrus (MTG) tissue obtained from AD patients $(n=45)$ and elderly, non-demented controls $(n=35$; see Table 1 and the "Materials and methods" section for detailed demographics) [16]. This brain region was selected as the MTG is known as a site of early AD pathology [17], and differences in global levels of DNA methylation and hydroxymethylation have previously been reported in this brain region in $\mathrm{AD}$ [18]. While informative on its own, the inclusion of UC measurements also allows us to better compare our findings with previous studies using conventional BS conversion, since UC is determined by subtracting the BS signal $(5 \mathrm{mC}+5 \mathrm{hmC})$ from 1 (Fig. 1). Even though the effects will be opposite from directly using the BS signal, incorporating UC in our study represents a crucial legacy analysis that enables the comparison with previous studies solely relying on the BS signal. Moreover, mechanistically, as an example, the affinity of a transcription factor may be different in the presence of $\mathrm{UC}, 5 \mathrm{mC}$, or $5 \mathrm{hmC}$, implicating that differential levels of UC (in the absence of significantly different $5 \mathrm{mC}$ or $5 \mathrm{hmC}$ levels) may have direct functional implications on gene expression. We followed up the brain analysis exploring DNA methylation in whole blood in an independent cohort, including samples from $\mathrm{AD}$-converters and non-converters at two time points, before (54 converters, 42 controls) and after (41 converters, 42 controls) conversion to clinical AD (see Table 2 and the "Materials and methods" section for detailed demographics). Blood DNA methylomic markers were measured using only BS-converted DNA, as $5 \mathrm{hmC}$ has a very low prevalence in blood [8].

\section{Results}

\section{Middle temporal gyrus}

Site-specific $5 \mathrm{mC}, 5 \mathrm{hmC}$, and UC levels were determined for the MTG using Illumina's Infinium HumanMethylation450K microarray (HM 450K array) with BS and oxBS-converted DNA (Fig. 1; see Tables 1 and 2 for cohort demographics). An epigenome-wide association study (EWAS) was performed for each DNA modification to identify the association with AD. The adjusted linear models showed no signs of inflation (all lambda values were between 0.95 and 1.05; see Additional file 2: Figure S1 for QQ plots). None of the AD-associated CpG sites in the MTG passed false discovery rate (FDR) correction (Additional file 1: Tables S1-S3).

A structural and functional genomic annotation enrichment analysis on the 1000 highest ranked sites indicated a significant enrichment of several CpG island features, gene features, and alternative transcription events. This included an enrichment of mainly gene body sites for the $5 \mathrm{mC}$ (fold enrichment $=1.42, p=1.17 \mathrm{E}-10$ ) and $5 \mathrm{hmC}$ (fold enrichment $=1.17, p=3.64 \mathrm{E}-03$ ) results and mainly intergenic sites for the UC (fold enrichment $=1.59, p=1.67 \mathrm{E}-09$ ) results (Additional file 2: Figure S8; Additional file 1: Table S7).

A regional analysis, looking at the spatial correlation of adjacent modified positions, detected 1 differentially methylated region (DMR), 1 differentially hydroxymethylated region (DHR), and 11 differentially unmodified regions (DURs) that were associated with AD in the MTG (Table 3; Additional file 2: Figure S3). Analysis of MTG expression data of genes annotated to DMRs, DHRs, and DURs showed a significant negative correlation between a DUR associated with RHBDF2 and RHBDF2 RNA expression $\left(\rho=-0.39, p_{F D R}=4.37 \mathrm{E}-03\right)$ (Additional file 1: Table $\mathrm{S10}$ ). Of note, although the DHR residing in the transcription start site (TSS) of CHRNB1, of which all probes show hyperhydroxymethylation in the AD cases, did not correlate with CHRNB1 mRNA expression $\left(\rho=-0.09, p_{F D R}>\right.$ $0.05)$, a linear regression analysis of regressed MTG expression data of CHRNB1 showed a significant elevation of CHRNB1 mRNA levels in AD cases (estimate $=0.13$, 


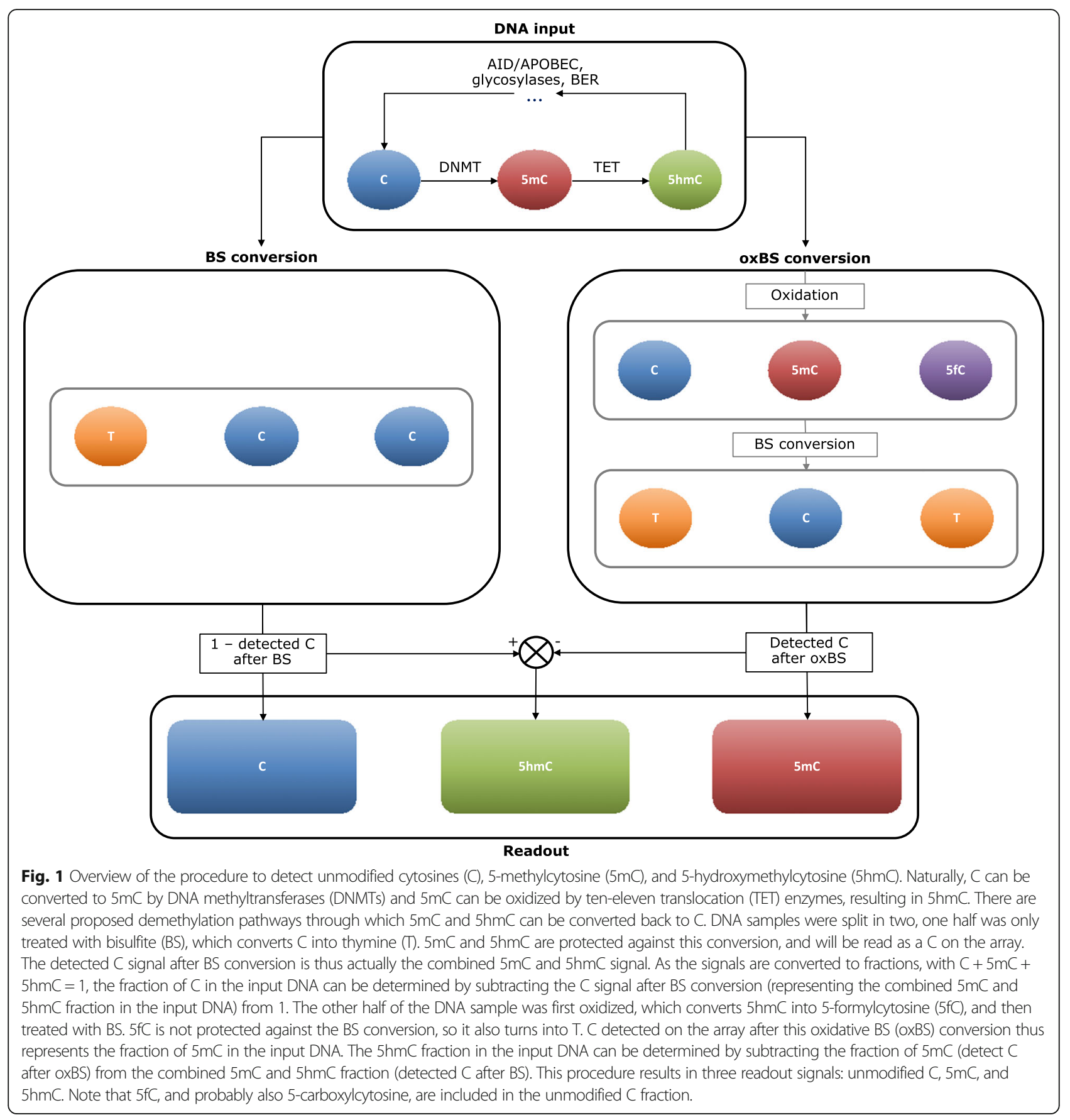

$p=1.37 \mathrm{E}-04$ ) (Additional file 2: Figure S4). For a full transcriptomic investigation of the MTG cohort used in the present study, see the recent publication of Piras et al. [19].

Next, a gene regulatory network (GRN) analysis was performed with the unique genes annotated to the 1000 highest ranked probes. Because of different numbers of associated genes from each dataset, we obtained contextualized networks with varying number of interactions. The number of interactions in the contextualized GRNs representing the differential $5 \mathrm{mC}, 5 \mathrm{hmC}$, and UC MTG states were 325, 398 and 244, respectively. Differential GRN analysis identified several candidate genes highly influential in the simulated transition from a diseased towards a healthy phenotype. Based on a score indicating for each gene, when changed, the number of other genes in the network that were predicted to show altered expression, IL6 (score $=55)$, SIAH1 (score =78), and EGF (score $=55$ ) were found to be the most influential in the $5 \mathrm{mC}, 5 \mathrm{hmC}$, and UC networks, respectively (Additional file 1: Table S9). 
Table 1 Cohort demographics-brain tissue

\begin{tabular}{lll}
\hline & AD patients & Non-demented controls \\
\hline$N$ & 45 & 35 \\
Gender(m/f) & $22 / 23$ & $17 / 18$ \\
Age of death (mean \pm SD) & $85.09(6.24)$ & $84.46(5.50)$ \\
PMI (Mean \pm SD) & $2.77(0.69)$ & $2.87(1.03)$ \\
Plaque total (mean \pm SD) & $12.97(2.25)$ & $4.65(4.30)$ \\
Tangle total (mean \pm SD) & $11.02(4.16)$ & $3.96(2.10)$ \\
Braak stage (range (median)) & II-VI (V) & I-IV (III)
\end{tabular}

The brain tissue cohort consisted of 80 middle temporal gyrus (MTG) tissue samples obtained from the Banner Sun Health Research Institute (Sun City, AZ, USA), from which HM 450K array BS and oxBS data was generated. Displayed is the number of samples in each group and the distributions of gender, age, postmortem interval (hours), Braak stage, and plaque and tangle total (the sum of average $A \beta$ plaque densities and tangle densities (resp.) in the entorhinal cortex, hippocampus, parietal lobe cortex, temporal lobe cortex and frontal lobe cortex

\section{Blood}

Since $5 \mathrm{hmC}$ is not enriched in the blood, only BS conversion was used to measure site-specific $5 \mathrm{mC}$ levels, also with the HM 450K array. A blood EWAS investigating the association between DNA methylation and conversion to AD was performed at baseline and at follow-up, leading to the identification of 3 differentially methylated positions at baseline and 266 at follow-up (Additional file 1: Tables S4-S6). No significant inflation was detected (Additional file 2: Figure S2; see the "Materials and methods" section for details).

Genomic annotation enrichment analysis of the top sites in blood showed enrichment of mainly intergenic sites (fold enrichment $=1.32, p=5.80 \mathrm{E}-04$ ) at baseline and proximal promoters (fold enrichment $=0.79, p=1.60 \mathrm{E}-04$ ) at followup (Additional file 2: Figure S9; Additional file 1: Table S8).

Table 2 Cohort demographics_-blood samples

\begin{tabular}{lll}
\hline & Controls & Converters \\
\hline Baseline (T1) & & \\
$N$ & 42 & 54 \\
Gender (m/f) & $10 / 32$ & $17 / 34$ \\
Age at baseline (mean \pm SD) & $81.00 \pm 3.11$ & $82.31 \pm 3.55$ \\
APOE4 carriers & $43 \%$ & $43 \%$ \\
Follow-up (T2) & & \\
N & 42 & 41 \\
Gender (m/f) & $10 / 32$ & $13 / 28$ \\
Age at baseline (mean \pm SD) & $81.00 \pm 3.11$ & $82.01 \pm 3.51$ \\
APOE4 carriers & $43 \%$ & $41 \%$ \\
\hline
\end{tabular}

Blood samples were obtained from the German Study on Ageing, Cognition and Dementia in Primary Care Patients (AgeCoDe) cohort, and HM 450K array BS data was generated. The cohort includes controls, who showed no signs at baseline or follow-up, and converters who showed no signs of dementia at baseline, but were diagnosed with AD dementia at follow-up. DNA samples were collected at baseline and follow-up for both groups. Displayed is the number of samples in each group, the distributions of Gender and Age at baseline, and the percentage of APOE $\varepsilon 4$ allele carriers
The regional analysis found 15 and 21 DMRs associated with conversion to $\mathrm{AD}$ at baseline and follow-up, respectively (Table 4; Additional file 2: Figure S5).

GRNs representing the blood baseline and follow-up states contained 475 and 277 interactions, respectively. Differential GRN analysis identified WNT3A (score $=50$ ) as the most influential gene in the baseline network, and $\mathrm{SHH}$ $($ score $=33)$ in the follow-up network (Additional file 1: Table S9).

\section{Overlap}

Only 1 blood DMR, close to GLIPR1L2, showed hypermethylation in relation to AD conversion at both the baseline $\left(+2.72 \%, p_{\text {Šidák }}=1.40 \mathrm{E}-04\right)$ and follow-up $\left(+1.34 \%, p_{\check{S} i-}\right.$ dák $=6.94 \mathrm{E}-06)$ time points. Extracting the probes located in this blood GLIPR1L2 DMR from the MTG EWAS for comparison showed, in AD cases, lower UC levels (9/10 probes with negative $\log 2$ fold change $[\operatorname{logFC}]$ ), mixed changes for $5 \mathrm{mC}(6 / 10$ probes with positive $\operatorname{logFC})$, and lower $5 \mathrm{hmC}$ levels for the probes that passed the detection threshold ( $2 / 2$ probes with negative $\operatorname{logFC})$. Even though the UC observations in the MTG are in line with the blood findings, only for one UC probe (cg07311024) the change was nominally significant $(\operatorname{logFC}=-0.01, p=$ $3.88 \mathrm{E}-02)$. A targeted linear regression analysis of the regressed MTG expression data of GLIPR1L2 showed a significant decrease in $\mathrm{AD}$ cases (estimate $=-0.10, p=$ 3.12E-04) (Additional file 2: Figure S6).

Interestingly, close to the TSS of OXT, we observed a DMR which was detected both in the MTG $\left(-3.76 \%, p_{\check{S} i-}\right.$ dák $=1.07 \mathrm{E}-06$ ), as well as in the blood dataset (at baseline, $+3.43 \%, p_{\text {Šidák }}=7.14 \mathrm{E}-04$ ) (see Additional file 2: Figure S7 for the probe positions of both OXT DMRs). MTG OXT methylation across Braak stages, as a proxy indicator of disease progression, is displayed in Fig. 2 and suggest OXT hypermethylation towards Braak 3-4 stages and OXT hypomethylation during later stages. Moreover, in the differential GRN analysis, OXT came forward as an influential gene. In case of the $5 \mathrm{mC}$ and $5 \mathrm{hmC}$ MTG states, a change in OXT was predicted to alter the expression of 39 and 54 other genes in the networks, respectively, and in the blood baseline state, OXT was predicted to alter 41 genes in the network (Additional file 2: Figures S10-S12; Additional file 1: Table S9).

\section{Discussion}

For the current study, we aimed to identify AD-related changes in epigenetic DNA modifications, comparing brain tissue from $\mathrm{AD}$ patients and age-matched controls. In addition, we explored DNA methylation in blood samples from $\mathrm{AD}$-converters and non-converters, both at a preclinical stage and after conversion, identifying an $\mathrm{AD}$-associated DMR in OXT in both the brain and blood datasets. 
Table 3 Differentially methylated, hydroxymethylated, and unmodified regions in the middle temporal gyrus

\begin{tabular}{|c|c|c|c|c|c|c|}
\hline Gene & Position & Gene feature & $n$ & $p$ value & Šidák $P$ & Average $\Delta \%$ (range $\Delta \%)$ \\
\hline \multicolumn{7}{|l|}{$5 m C$} \\
\hline OXT & chr20:3051954-3052484 & TSS; Intron; 5'UTR; CDS & 10 (0 up; 10 down) & $1.43 E-09$ & 1.07E-06 & $-3.76(-6.94:-0.43)$ \\
\hline \multicolumn{7}{|l|}{$5 \mathrm{hmC}$} \\
\hline CHRNB1 & chr17:7348322-7348439 & TSS; Exon; 5'UTR & 5 (5 up; 0 down) & 2.63E-07 & 4.01E-04 & $1.46(0.70: 1.96)$ \\
\hline \multicolumn{7}{|l|}{ UC } \\
\hline ACTR3C; LRRC61 & chr7:150019955-150020946 & TSS; Intron; Exon; 5'UTR & 17 (1 up; 16 down) & $3.54 \mathrm{E}-12$ & $1.42 \mathrm{E}-09$ & $-0.57(-1.34: 0.02)$ \\
\hline RHBDF2 & chr17:74475240-74475403 & Intron; CDS & 5 (0 up; 5 down) & $1.99 \mathrm{E}-09$ & $4.85 \mathrm{E}-06$ & $-3.45(-4.71:-1.42)$ \\
\hline TMC8 & chr17:76128522-76128907 & Intron; CDS & 8 (0 up; 8 down) & $3.29 \mathrm{E}-09$ & $3.39 \mathrm{E}-06$ & $-1.26(-2.84:-0.26)$ \\
\hline$A S P G$ & chr14:104551867-104552210 & TSS; Intron; 5'UTR; CDS & 5 (0 up; 5 down) & $1.00 \mathrm{E}-08$ & $1.16 \mathrm{E}-05$ & $-1.21(-2.49:-0.28)$ \\
\hline PIEZO1 & chr16:88844969-88845205 & Intron & 3 (0 up; 3 down) & $1.87 \mathrm{E}-07$ & $3.14 \mathrm{E}-04$ & $-3.08(-3.76:-2.32)$ \\
\hline WWAT & chr6:31734106-31734472 & Intron; CDS & 10 (10 up; 0 down) & $2.04 \mathrm{E}-07$ & $2.21 \mathrm{E}-04$ & $3.39(2.24: 4.23)$ \\
\hline CLMAT3; SPARC & chr5:151066460-151066731 & Exon; TSS; 5'UTR & 6 (0 up; 6 down) & $5.21 \mathrm{E}-07$ & 7.62E-04 & $-0.29(-0.64: 0.21)$ \\
\hline KIAA1522 & chr1:33231070-33231314 & TSS; Exon; 5'UTR; Intron & 6 (0 up; 6 down) & $8.48 \mathrm{E}-07$ & $1.38 \mathrm{E}-03$ & $-1.85(-2.43:-1.3)$ \\
\hline C3 & chr19:6713227-6713460 & Intron; CDS & 3 (1 up; 2 down) & $9.21 \mathrm{E}-07$ & $1.57 \mathrm{E}-03$ & $-1.20(-2.1: 0.46)$ \\
\hline PRSS22 & chr16:2908157-2908246 & TSS; Exon; 5'UTR & 4 (0 up; 4 down) & $1.02 \mathrm{E}-06$ & $4.52 \mathrm{E}-03$ & $-1.56(-1.91:-1.39)$ \\
\hline FRAT1 & chr10:99080756-99081017 & Exon & 3 (3 up; 0 down) & $1.50 \mathrm{E}-06$ & $2.28 \mathrm{E}-03$ & $2.34(1.57: 3.03)$ \\
\hline
\end{tabular}

Differentially methylated $(5 \mathrm{mC})$, hydroxymethylated $(5 \mathrm{hmC})$, and unmodified (UC) regions in a comparison of Alzheimer's disease patients $(n=45)$ and controls $(n=35)$. Displayed for each region is the UCSC gene name, chromosomal position (genome build 37), gene feature (TSS, transcription start site; $5^{\prime} \mathrm{UTR}, 5^{\prime}$ untranslated region; CDS, coding sequence), number of probes in region and number of upregulated and downregulated probes ( $n$ ), $p$ value and multiple testingcorrected $p$ (Šidák- $P$ ), and average change in beta value (Alzheimer's disease - control), including the range of the probe differences

The DHR identified in the MTG resided in the promotor of CHRNB1, which encodes acetylcholine receptor subunit beta and is important for cholinergic neurotransmission. In combination with the observed increased levels of CHRNB1 mRNA in the MTG, this potentially reflects a compensatory mechanism to maintain acetylcholine signaling in $\mathrm{AD}$. Indeed, the acetylcholine-related pathway is known to be altered in $\mathrm{AD}$ and, as such, remains an important target in the development of novel treatment options [20]. Previous epigenomic studies of $\mathrm{AD}$ using standard $\mathrm{BS}$-conversion have found associations between $\mathrm{AD}$ and $R H B D F 2$ methylation in multiple cortical regions [3, 4]. We replicated these findings; observing an AD-associated DUR in $R H B D F 2$, which included the previously detected CpG sites (cg13076843, cg05810363, and cg12163800) and showed the same direction of effect as previously reported. For instance, using conventional bisulfite (BS) conversion, a $3.36 \%$ increase in DNA methylation level of cg05810363 has been observed across cortical regions in association with AD neuropathology [3]. Interestingly, a negative correlation between UC levels within the RHBDF2 DUR and RHBDF2 mRNA expression was observed in the MTG. RHBDF2 is thought to be important for the release of tumor necrosis factor, a major inflammatory cytokine associated with neuroinflammation observed in $\mathrm{AD}[21,22]$. $C 3$, another gene with an $\mathrm{AD}$ associated DUR, encodes a central component of the complement system and mediates developmental synapse elimination by phagocytic microglia. $C 3$ has previously been implicated in mediating synaptic loss in the early stages of $\mathrm{AD}[23]$.

The top DMR from the baseline blood analysis, showing hypermethylation in $\mathrm{AD}$, is close to the LDLRAD4 gene. This gene has previously been associated with schizophrenia and blood pressure and is thought to suppress transforming growth factor (TGF)- $\beta$ signaling [24-27]. TGF- $\beta$ is an inflammatory cytokine playing a role in cell survival and synaptic transmission, and various isoforms have been associated with AD [28]. Additional baseline blood DMRs were close to TENM3, involved in neurite growth [29], $S Y M P K$, involved in polyadenylation regulation of gene expression and which showed increased expression in $\mathrm{AD}$ [30], SLC44A4, associated with type 1 diabetes mellitus and human aging [31], ZMAT2, which had decreased expression in AD [32], ULK1, which may play a role in the autophagic degradation of amyloid beta (A $\beta$ ) [33], and RUNX2, which links bone health and cognitive function and anxiety-like behavior [34]. The DMR that was found both at baseline and follow-up is associated with GLIPR1L2. GLIPR1L2 also showed decreased expression in the MTG. The function of this gene is not well known, but it may play a role in tumor suppression and immune function [35, 36]. The top AD-associated blood DMR at follow-up, showing hypomethylation, is located in GSDMD, which encodes a critical factor in pyroptosis; a form a cell death that may be triggered by $A \beta[37,38]$. Other genes with a nearby $\mathrm{AD}$-associated blood DMR at 


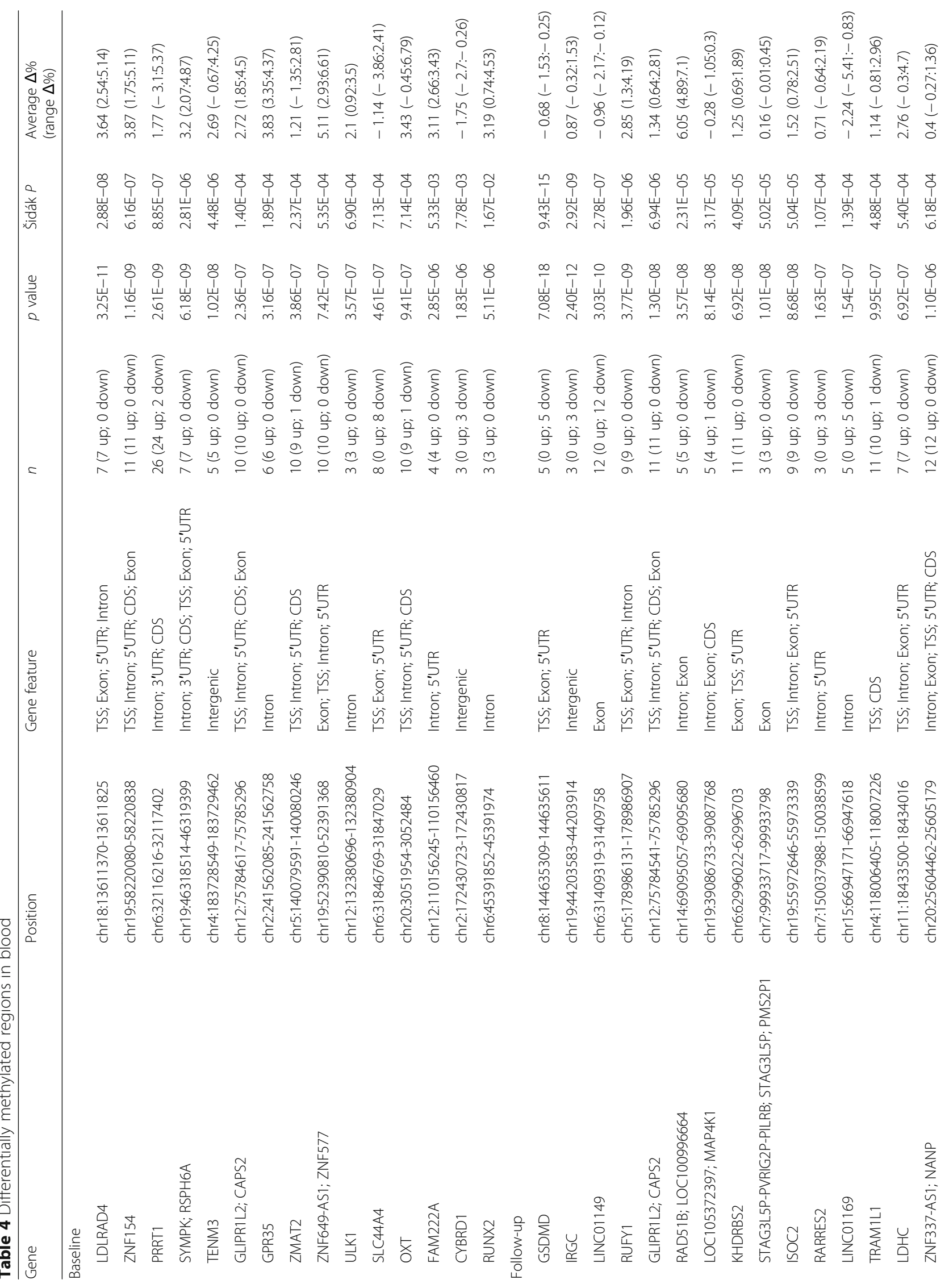




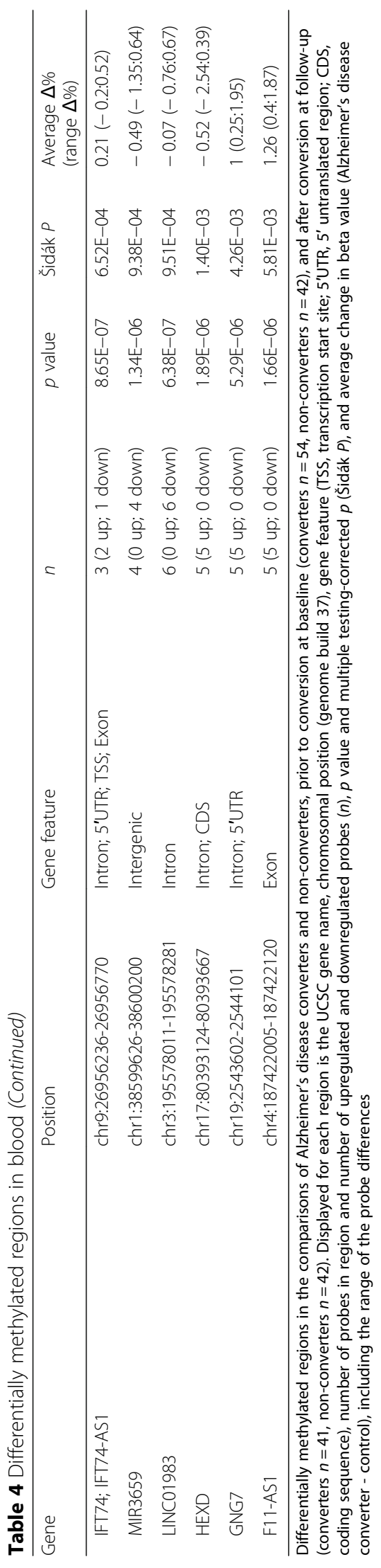




\section{OXT}

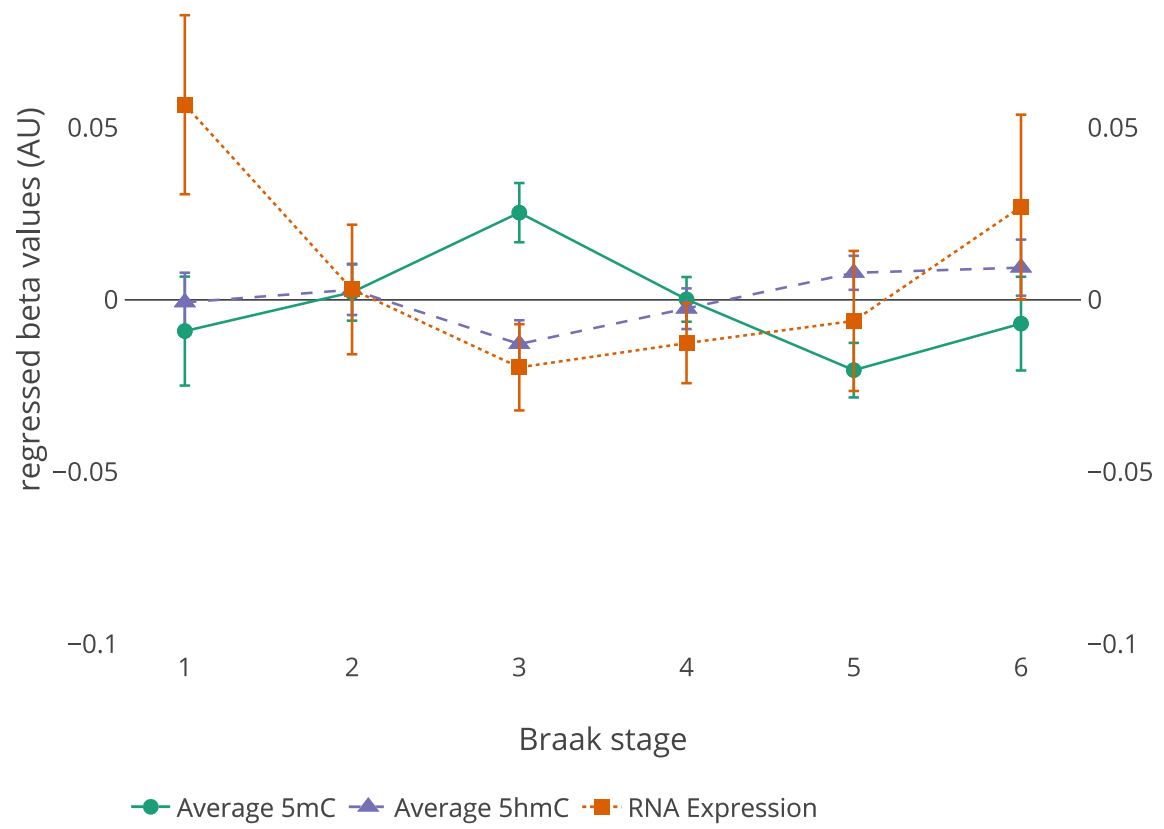

Figure 2. Methylation, hydroxymethylation and expression of OXT across Braak staging. Regressed OXT expression values and average regressed $5 \mathrm{mC}$ and $5 \mathrm{hmC}$ values of 10 and 9 overlapping probes within the OXT DMR are shown. Regressed values were generated by taking the residuals of a model fitted with the covariates age, gender, and 5 surrogate variables, but excluding the predictor of interest AD diagnosis. Error bars represent mean \pm SEM. $N=76$ for each line.

follow-up include $K H D R B S 2$, previously identified in a genome-wide association interaction analysis in relation to $\mathrm{AD}$ [39], RARRES2, encoding an adipokine that has been linked to inflammation, obesity, diabetes, and cardiovascular diseases [40], and GNG7, for which Braak stageassociated differential methylation has been reported in cortical glial cells of AD patients [41].

Taken together, the observation of epigenetic modifications in several inflammation-associated genes in both brain and blood aligns with the amyloid cascadeinflammatory hypothesis of AD [42]. These findings could reflect either downstream effects resulting from the inflammatory activation seen in $\mathrm{AD}$, or, particularly in the brain, reflect mediating effects of DNA modifications on inflammation as a causative factor. Exploring the exact nature of the AD-associated epigenetic modifications in inflammation-associated genes and the potential for blood biomarkers is thus a pivotal aim for future studies.

Strikingly, our methylomic profiling in MTG and whole blood both led to the identification of a common DMR associated with $\mathrm{AD}$, close to the transcription start site of OXT. Our design allowed for the disentanglement of specific $5 \mathrm{mC}$ and $5 \mathrm{hmC}$ signals in the MTG, which, in the case of $O X T$, suggests they change in opposite directions in relation to $\mathrm{AD}$. The detection of a DMR near OXT is in line with a recent report of a nearly identical AD-associated OXT DMR (containing 1 additional probe) in the superior temporal gyrus (STG) [43]. This area is located directly above the MTG. Furthermore, using GRN analysis addressing the overlap between the top influential genes in the networks and genes with significant differentially modified regions, we observed $O X T$ to consistently appear as one of the most influential genes in both brain and blood GRNs. OXT encodes oxytocin, a neuropeptide involved in the neuromodulation of social behavior, stress regulation, and associative learning [44]. Interestingly, the functional impact of OXT promoter methylation at the same genomic locus has been recently shown [45]. It was linked to several measures of sociability, superior temporal sulcus activity during social cognition tasks, as well as fusiform gyrus gray matter volume, a brain region closely related to the MTG.

The paraventricular nucleus and supraoptic nucleus are thought to be the main sites of central oxytocin production [46], areas which reportedly undergo cell loss during $A D$ [47]. The remaining neurons are thought to undergo a, potentially compensatory, hypertrophy. One might hypothesize that this activation could initially lead to higher than normal oxytocin levels, before synthesis collapses during the final stages of AD. Interestingly, enhanced levels of hippocampal oxytocin have been 
associated with memory impairment, and $\mathrm{AD}$-associated elevations of oxytocin have been reported in the hippocampus and temporal cortex [48]. There is also limited evidence oxytocin is reduced in cerebrospinal fluid of manifest AD [49]. Additionally, it has been suggested that co-damage to the locus coeruleus and hypothalamic nuclei could happen early during $\mathrm{AD}$ pathogenesis [50], substantiating the hypothesis that oxytocin could serve as an early diagnostic biomarker for AD.

In line with an $\mathrm{AD}$-related increase in temporal cortex oxytocin levels [48], all ten CpG sites within the MTG OXT DMR showed decreased levels of methylation in AD cases. Conversely, we observed $O X T$ hypermethylation in the DNA from peripheral blood of participants who progressed to dementia. The OXT blood DMR was not observed after conversion. Research has shown that independent mechanisms may be involved in peripheral and central regulation of OXT expression, supporting this apparent discrepancy observed in blood and brain [51]. Alternatively, these observations suggest there may be a temporal change in $O X T$ methylation during $\mathrm{AD}$ progression. Looking at MTG OXT methylation across Braak stages appears to support the observation of OXT hypermethylation at earlier stages, as also seen in the blood, and OXT hypomethylation at more advanced stages. Notably, it has recently been reported that oxytocin administration was able to improve social cognition and behavior in frontotemporal dementia patients [52], illustrating the complex modulatory function of oxytocin in different brain regions and its potential use in the treatment of certain manifestations of dementia. Whether oxytocin represents a suitable therapeutic agent for $\mathrm{AD}$ remains to be elucidated.

Even though we detect several targets relevant in light of $\mathrm{AD}$, a general lack of overlap between the different analyses presented here might be noted, an observation which is true for EWAS and epigenetics studies in AD in general. Others have discussed a myriad of possible reasons for discrepancies between studies, such as methodological differences, differences in tissue type and processing, study designs, and samples sizes [53]. In view of this, the detection of a common OXT DMR in two completely independent cohorts and two different types of tissue, further supported by a recent similar EWAS on the STG [43], makes it an even more promising target for future studies. However, the differences in direction of change and the OXT methylation pattern observed over Braak stages indicates these epigenetic changes should be further studied in a longitudinal fashion to establish a clear relationship with $\mathrm{AD}$ neuropathology, as well as clinical manifestations of AD.

Given the detection of several regions of interest, it should be noted that the lack of positions significantly associated with AD in the MTG after FDR correction may be the result of a limited sample size. Genome-wide site-specific AD- related epigenetic changes should thus be further investigated using studies with larger sample sizes or metaanalyses. Alternatively, future studies may focus on candidate genes identified in the present work, such as OXT.

\section{Conclusions}

Our novel approach confirms some previous epigenetic findings identified in the central nervous system, including $R H B D F 2$, as well as revealed novel targets, such as in CHRNB1, involving dysregulated DNA hydroxymethylation. Furthermore, the nearly identical OXT DMRs found in both the blood and brain suggest a systemic epigenetic dysregulation in $\mathrm{AD}$ involving OXT. The detection of the OXT DMR at pre-dementia stages suggests its potential relevance as a novel biomarker and may offer new treatment strategies to be explored in future studies.

\section{Materials and methods \\ Patients}

Informed consent was obtained from all human participants. This includes donors of the Banner Sun Health Research Institute (BSHRI) Brain and Body Donation Program (BBDP), who signed an Institutional Review Board-approved informed consent form, including specific consent to the use of donated tissue for future research [16, 54]. The German Study on Ageing, Cognition and Dementia in Primary Care Patients (AgeCoDe) study protocol was approved by the local ethics committees at the University of Bonn (Bonn, Germany), the University of Hamburg (Hamburg, Germany), the University of Duesseldorf (Duesseldorf, Germany), the University of Heidelberg/Mannheim (Mannheim, Germany), the University of Leipzig (Leipzig, Germany), and the Technical University of Munich (Munich, Germany).

DNA from the MTG was obtained from $82 \mathrm{AD}$ patients and neurologically normal control BBDP donors stored at the Brain and Tissue Bank of the BSHRI (Sun City, AZ, USA) [16, 54] (Table 1). The organization of the BBDP allows for fast tissue recovery after death, resulting in an average post-mortem interval of only 2.8 $h$ for the included samples. Braak staging was carried out for AD neurofibrillary pathology. A consensus diagnosis of $\mathrm{AD}$ or non-demented control was reached by following National Institutes of Health AD Center criteria [54]. Comorbidity with any other type of dementia, cerebrovascular disorders, mild cognitive impairment (MCI), and presence of non-microscopic infarcts was applied as exclusion criteria. Although this may limit the generalizability of the current study, these strict exclusion criteria were applied to enhance the detection of AD-specific dysregulation, not confounded by common comorbidities. Detailed information about the BBDP has been reported elsewhere [16, 54].

AgeCoDe is a prospective longitudinal study including 3327 non-demented individuals at baseline, initiated to 
investigate the early detection of $\mathrm{MCI}$ and dementia in primary care [55]. Participants were randomly selected from the general practice registry in six German cities and cognition was assessed at approximately 18-month intervals and 10-month intervals after visit 7, for up to 11 years after baseline. For this study, whole blood DNA was obtained from a subsample of 99 individuals aged above 75 years from this AgeCoDe cohort (Table 2). Of these, 42 were converters: they had no dementia at baseline, had DNA samples available at baseline and followup (after $\sim 4.5$ years), and had sufficient information available for a diagnosis of $\mathrm{AD}$ dementia to be made at the 4.5-year follow-up. There were 44 control subjects, who had to adhere to the same criteria, except that they should have no signs of dementia at neither baseline, nor the 4.5-year follow-up, and all subsequent cognitive assessments up to 11 years after baseline. The remaining 13 participants had not yet converted at the 4.5-year follow-up (when blood was drawn), but were diagnosed during a later follow-up, up to a maximum of 11 years after baseline [56]. These samples were grouped together with the other converters.

The groups were matched for age, gender, and $A P O E$ genotype. The presence of dementia was assessed in all subjects with the Structured Interview for Diagnosis of Dementia of Alzheimer Type, Multi-infarct Dementia, and Dementia of Other Etiology [57] based on the DSMIV criteria. The dementia diagnosis in subjects who were not personally interviewed was based on the Global Deterioration Scale [58] $(\geq 4)$ and the Blessed Dementia Rating subscales. The etiological diagnosis of $\mathrm{AD}$ was based on the criteria of the National Institute of Neurological and Communicative Disorders and Stroke and the Alzheimer's Disease and Related Disorders Association [59] for probable AD and was only assigned in case of sufficient information provided. All final diagnoses were a consensus between the interviewer and an experienced geriatrician or geriatric psychiatrist. More detailed information about the AgeCoDe cohort has been published previously $[55,56]$.

\section{(Hydroxy)Methylomic profiling}

For the BBDP samples, the TrueMethyl ${ }^{\mathrm{TM}} 24$ Kit version 2.0 by CEGX $^{\mathrm{TM}}$ (Cambridge Epigenetix Limited, Cambridge, UK) was used for BS and oxBS conversion of genomic DNA (gDNA) extracted from frozen MTG tissue. All laboratory procedures were performed at GenomeScan (GenomeScan B.V., Leiden, the Netherlands), without knowledge of the phenotypic characteristics of the samples and according to the manufacturer's instructions. Prior to conversion, high molecular weight (HMW) gDNA was quantified using a PicoGreen assay (Invitrogen, Carlsbad, CA, USA), and gel-electrophoresis was performed to assess gDNA quality. All samples were of sufficient quantity and quality. A volume of $1 \mu \mathrm{g}$ HMW gDNA was used per sample, which, after purification and denaturation, was split into two samples that underwent either DNA oxidation (oxBS samples) or mock DNA oxidation (BS samples). Subsequently, all samples were BS-treated, and the yield of the samples was assessed by a Qubit ssDNA assay (Invitrogen). An additional quality control, using a restriction enzyme only able to cut unconverted cytosines, was performed for a qualitative assessment of $5 \mathrm{hmC}$ oxidation and BS conversion. From each BS/oxBS-treated DNA sample, $8 \mu \mathrm{L}$ was amplified and hybridized on HM $450 \mathrm{~K}$ arrays (Illumina, Inc., San Diego, CA, USA), and the Illumina iScan was used for imaging of the array. Sample preparation, hybridization, and washing steps for the Illumina Infinium Methylation Assay of the BeadChip arrays were performed according to the manufacturer's protocol.

For the AgeCoDe samples, gDNA was isolated from whole blood and DNA concentration and purity was determined using the NanoDrop ND1000 spectrophotometer (Thermo Fisher Scientific). All samples were of sufficient quantity and quality. Five hundred nanograms of gDNA was used for BS conversion, using a Qiagen EpiTect 96 Bisulfite Kit (Qiagen, Hilden, Germany) according to the manufacturer's protocol. A total of $200 \mathrm{ng}$ of BS converted DNA was analyzed using HM 450K arrays according to the manufacturer's instructions. The Illumina iScan was used for imaging of the array.

\section{Transcriptomic profiling}

Total RNA extracted from frozen MTG, from matched samples as used for the epigenetic MTG analyses, was isolated with the RNeasy Mini Kit (Qiagen) starting with at least 60 $\mathrm{mg}$ of tissue. Raw expression data was obtained at the BSHRI, using the HumanHT-12 v4 BeadChip (Illumina).

\section{Statistical analysis}

All computational and statistical analyses were performed using the statistical programming language $R$ (version 3.3.2) [60] and RStudio (version 1.0.136) [61], unless otherwise specified. Raw IDAT files from the Illumina iScan were loaded into $\mathrm{R}$ using the minfi package (version 1.20.2) [62]. To confirm that the longitudinal samples were from the same donor a genetic fingerprinting test was performed based on the 65 SNP probes included on the HM $450 \mathrm{~K}$ chip, as implemented in the ewastools package [63]. Based on this test, 2 donors with mismatching samples were detected and excluded from the blood data. Next, the gender of the samples was predicted based on $\mathrm{X}$ chromosome methylation using the DNAmArray package (version 0.0.2) [64], compared with the assumed gender, and mismatches were excluded (1 mismatched sample was excluded from the blood data). Cross-hybridizing probes and probes containing a 
common SNP in the sequence or within $10 \mathrm{bp}$ of the sequence were removed [65]. The "pfilter" function of the wateRmelon package (version 1.18.0) [66] was used for probe filtering (6 969 and 1437 probes were removed from the MTG and blood data, respectively). The remaining probe data was normalized using the dasen method, as implemented in the wateRmelon package [66]. Probes on the $\mathrm{X}$ and $\mathrm{Y}$ chromosomes were excluded from further analyses.

Following normalization, two sets of beta values, from the standard BS arrays $(5 \mathrm{mC}+5 \mathrm{hmC})$ and from the oxBS arrays $(5 \mathrm{mC})$, were generated in case of the MTG. By subtracting oxBS beta values from the BS beta values $\left(\Delta \beta_{\mathrm{BS} \text {-oxBS }}\right)$ for each probe in each sample, $5 \mathrm{hmC}$ levels were calculated (Fig. 1). UC values were determined as $1-B S\left(1-\beta_{B S}\right)$. It should be noted that other DNA demethylation intermediates, such as 5-formylcytosine (5fC) and 5-carboxylcytosine may be represented in the BS or UC levels, as it is currently unclear how these intermediates respond to oxBS conversion [67]. However, these intermediates are present at very low levels and are not enriched in brain tissue like $5 \mathrm{hmC}$ is [68]. In order to reduce noise and filter out nonhydroxymethylated sites, outliers deviating more than $\pm 2 \mathrm{SD}$ from the probe mean in the $5 \mathrm{hmC}$ dataset were determined and set to the mean \pm 2 SD first, and subsequently, a threshold of zero was applied to the mean of individual probes $(218,0095 \mathrm{hmC}$ values were excluded). Boxplots and density plots of raw and normalized beta values per sample were inspected for clear outliers (2 MTG samples were excluded due to clear deviation from the other samples; data not shown). After data processing, 80 MTG and 96 blood samples remained, with 396,600 remaining probes for MTG $5 \mathrm{mC}$ and UC, 178,591 5hmC MTG probes, and 402,480 remaining probes in the blood datasets. The case-control analysis of the blood baseline data included all 96 samples (54 converters, 42 controls), while follow-up data included 83 samples, including the 41 converters that had already converted to $\mathrm{AD}$ at the 4.5-year follow-up and excluding those that had converted later. All individuals in the followup analysis were also included in the baseline analysis.

An initial model with beta values as outcome, AD diagnosis/conversion as predictor, and age and gender as covariates was used for a surrogate variable (SV) analysis with the sva package (version 3.22.0) [69]. The first 5 SVs of this analysis were added to the model to adjust for unobserved confounders, including potential batch effects and differences in cell type composition. As the addition of SVs still resulted in inflation of the regression statistics (lambda $=1.43$ ) of the blood follow-up analysis, and none of the SVs strongly correlated with the HM 450K chip IDs (which was the case for the other analyses), the chip IDs were also added to the model for this analysis. This successfully eliminated the inflation (lambda = 1.00).
Linear regression was performed using the limma package (version 3.30.11) [70] to test the association between the beta values and AD diagnosis/conversion. Test statistics were adjusted for bias and inflation with the bacon package (version 1.2.0) [71]. An FDR correction for multiple testing was applied to the $p$ values to identify differentially (hydroxy)methylated and unmodified positions (probes with $p_{F D R}<0.05$ ). Individual probes were annotated using Illumina UCSC annotation.

To examine the distribution of $5 \mathrm{mC}, 5 \mathrm{hmC}$, and UC levels across genomic regions, we annotated the 1000 highest ranking probes (Additional file 1: Tables S2-S7) using ENCODE annotation data, as described by Slieker et al. [72]. Fisher's exact test was used to assess enrichment in specific genomic regions.

To identify differentially (hydroxy)methylated and unmodified regions (DHRs/DMRs/DURs), spatial correlations between $p$ values of the association analysis were determined using comb- $p$ [73] with a seeding $p$ value of 0.01 and a window size of $1000 \mathrm{bp}$. Obtained $p$ values were StoufferLiptak-Kechris corrected for adjacent $p$ values and were subsequently corrected for multiple testing using the Šidák correction. Of the regions detected by comb-p, only those containing at least $3 \mathrm{CpGs}$ and having a $p_{\text {Šidák }}<0.05$ were accepted as differentially modified regions.

GRNs have been extensively used to achieve deeper understanding of disease related mechanisms [74]. Different topological characteristics of these networks, such as connectivity of nodes [75] or gene-gene interaction tendency in cell/tissue specific contexts [76], have been used to predict disease-related genes. Here, we have employed an in-house developed differential GRNs inference approach [77], which relies on gene expression data to infer GRNs specific to a given gene expression program. The initial set of interactions among the genes of interest was compiled from literature-based database ARIADNE [78] and consists of interactions belonging to the categories of "Direct Regulation," "Expression," and "Promoter Binding." The obtained set of interactions is not context-specific as they are reported to happen in different cell/tissue types and organisms. To obtain context-specific networks from the literature interaction maps, the pruning of interactions incompatible with the gene expression state was carried out, which resulted in contextualized networks compatible with the given gene expression state of the system. As a differential expression setting was used here, we obtained two contextualized GRNs for each state, representing the different network topology of diseased and healthy phenotype. The differential network topology helps us in identifying the set of genes that are regulated by different transcription factors in both networks. These genes formulate an ideal set of candidate perturbagens, as to change their 
expression state we have to perturb them individually. The obtained contextualized networks were used to identify genes in the common elementary circuits (positive and negative circuits) that can also serve as a set of candidate genes for perturbation. Genes in elementary circuits have been reported to play a crucial role in maintaining network stability [79] and are considered as a necessary condition for a network to have an attractive cycle [80]. In this regard, genes present in the common elementary circuits are considered to be the backbone of the network and any perturbations in the expression levels of these genes might lead the system to deviate from the normal steady state of the system, which can be described as a transition from healthy to a diseased state. Once we obtained a set of optimal perturbation candidates, we performed single-gene perturbation simulations to see the effect of change in expression of a single gene on all the other genes in the GRN. This measure tells us about the influential capability of the selected gene in the network; the higher the number of downstream genes being affected by perturbing a candidate gene, the more crucial is its role in the regulation of other genes in the GRN.

Positions from the AD association analyses were ranked based on a combined $p$ value and $\log 2$ fold change ranking score. The GRN analysis was then conducted separately for the genes annotated to the 1000 highest ranked sites in the MTG $(5 \mathrm{mC}, 5 \mathrm{hmC}$, and UC separately) and blood (baseline and follow-up separately) (Additional file 1: Tables S2-S7). Closest UCSC TSS annotation was used to obtain unique genes. After applying the differential GRN analysis on the contextualized networks, we ranked the key candidate genes based on their scores. This score represents the number of genes whose gene expression is changed (shifted from diseased towards the healthy phenotype) upon perturbation of the candidate gene.

Raw RNA expression data was exported from Illumina's GenomeStudio (version 2011.1) with the Expression Module (v1.9.0) for further analysis in R. Of the 80 subjects used for the epigenetic analyses, 1 case was not included on the expression array, and 3 additional cases were excluded after quality control of the data, due to extreme outlying values or failed reads, leaving 76 subjects for further analyses. Data was quantile-quantile normalized. Using the same model as for the regression analysis, the sva package was used to determine SVs for the epigenetic and expression datasets. The effects of age, gender, and 5 SVs were regressed out of the epigenetic and expression data using limma (i.e., "regressed data" refers to the residuals of a model fitted with the covariates, excluding the predictor of interest, being AD diagnosis or conversion in this case). Spearman correlations were determined for the expression data and the average of the regressed beta values of the probes in the DMRs, DHRs, and DURs, as well as correlations between the different epigenetic markers $(5 \mathrm{mC}$, $5 \mathrm{hmC}$, and $\mathrm{UC})$ for these probes, using the Hmisc package (version 4.0-2) [81].

\section{Supplementary information}

Supplementary information accompanies this paper at https://doi.org/10. 1186/s13148-019-0755-5.

Additional file 1. All Supplementary Tables (1-10), including descriptions.

Additional file 2. All Supplementary Figures (1-12) and descriptions.

\section{Abbreviations}

5fC: 5-Formylcytosine; 5hmC: 5-Hydroxymethylcytosine; 5mC: 5Methylcytosine; AD: Alzheimer's disease; AgeCoDe: Study on Ageing, Cognition and Dementia in Primary Care Patients and Stroke and the Alzheimer's Disease and Related Disorders Association; A $\beta$ : Amyloid beta; BBDP: Brain and Body Donation Program; BS: Bisulfite; BSHRI: Banner Sun Health Research Institute; DHR: Differentially hydroxymethylated region; DMR: Differentially methylated region; DUR: Differentially unmodified region; EWAS: Epigenome-wide association study; FDR: False discovery rate; gDNA: Genomic DNA; GRN: Gene regulatory network; HM 450K array: Illumina's Infinium HumanMethylation450K microarray; HMW: High molecular weight; logFC: log2 fold change; MCl: Mild cognitive impairment; MTG: Middle temporal gyrus; oxBS: Oxidative BS; STG: Superior temporal gyrus; SV: Surrogate variable; TGF: Transforming growth factor;

TSS: Transcription start site; UC: Unmodified cytosine

\section{Acknowledgements}

We thank the donors and their families who made this research possible.

\section{Authors' contributions}

$\mathrm{RL}$, JAYR, and EP were responsible for data analysis, bioinformatics, interpretation of results, and drafting of the manuscript. ML, HW, LK, AK, PH, $\mathrm{TL}, \mathrm{SRH}, \mathrm{FJ}, \mathrm{WM}, \mathrm{MW}$, and AR supervised the AgeCoDe cohort, collected samples and patient data, and generated the blood data used for this project. Al, ARS, RGS, AdS, JM, and KL assisted in constructing the analysis pipeline for this project. LMTE was involved in analyzing the expression data and MA did the GRN analysis. RH, GK, and BPFR assisted in interpreting the results and forming the discussion section of the manuscript. $D M, E D$, and PDC represent the BSHRI-BBDP and supplied the MTG DNA samples and expression data. DvdH and AR conceived and designed the project. DvdH supervised the project and writing of the manuscript. All authors read and approved the final manuscript.

\section{Funding}

Funds have been provided by the Internationale Stichting Alzheimer Onderzoek (ISAO)/Alzheimer Netherlands (Award \#11532; Funded by the Dorpmans-Wigmans Foundation) (DvdH), the Baeter Laeve foundation, and by the Joint Programme-Neurodegenerative Disease Research (JPND) for the EPIAD consortium (http://www.neurodegenerationresearch.eu/wp-content/uploads/2015/10/Factsheet_EPI-AD.pdf). The project is supported through the following funding organizations under the aegis of JPND; The Netherlands, The Netherlands Organisation for Health Research and Development (ZonMw); United Kingdom, Medical Research Council; Germany, German Federal ministry of Education and Research (BMBF); Luxembourg, National Research Fund (FNR). This project has received funding from the European Union's Horizon 2020 research and innovation programme under Grant Agreement No. 643417. Additional funds have been provided by a fellowship as part of NWO grant 022.005.019 (RL) and the GW4 Biomed MRC Doctoral Training Partnership (JR). This research was further made possible by BReIN (Brightlands einfrastructure for Neurohealth), an initiative which is co-funded by the Province of Limburg, Maastricht University and Maastricht University Medical Centre + in the Netherlands. This publication was also funded in part by the German 
Federal Ministry of Education and Research (BMBF) (grants Nr: 01GI0710, 01GI0711, 01Gl0712, 01Gl0713, 01Gl0714, 01GI0715, 01GI0716, 01ET1006B). Analyses were also funded by the German Federal Ministry of Education and Research (BMBF 01EA1410A) within the project "Diet-Body-Brain: from epidemiology to evidence-based communication".

\section{Availability of data and materials}

The datasets generated from the BSHRI-BBDP samples and analyzed during the current study are available in the Gene Expression Omnibus (GEO; https://www.ncbi.nlm.nih.gov/geo/) repository, under GEO accession numbers GSE109627 and GSE109887 for the epigenetic and expression data, respectively. The datasets generated from the AgeCoDe samples and analyzed during the current study are not publicly available as participants did not provide informed consent for this, but are available from the corresponding author on reasonable request.

\section{Ethics approval and consent to participate}

Donors of the BBDP signed an Institutional Review Board-approved informed consent form, including specific consent to the use of donated tissue for future research $[16,54]$. The AgeCoDe study protocol was approved by the local ethics committees at the University of Bonn (Bonn, Germany), the University of Hamburg (Hamburg, Germany), the University of Duesseldorf (Duesseldorf, Germany), the University of Heidelberg/Mannheim (Mannheim, Germany), the University of Leipzig (Leipzig, Germany), and the Technical University of Munich (Munich, Germany).

\section{Consent for publication}

Not applicable.

\section{Competing interests}

The authors declare that they have no competing interests

\section{Author details}

${ }^{1}$ School for Mental Health and Neuroscience (MHeNS), Department of Psychiatry and Neuropsychology, Maastricht University, P.O. Box 616, 6200, MD, Maastricht, the Netherlands. ${ }^{2}$ Department of Psychiatry and Psychotherapy, University Medical Center Göttingen, 37075 Göttingen, Germany. ${ }^{3}$ University of Exeter Medical School, University of Exeter, Exeter, UK. ${ }^{4}$ Division of Neurogenetics and Molecular Psychiatry, Department of Psychiatry and Psychotherapy, University of Cologne, Medical Faculty, 50937 Cologne, Germany. ${ }^{5}$ Department of Neurodegeneration and Gerontopsychiatry, University of Bonn, 53127 Bonn, Germany. ${ }^{6}$ Department of Bioinformatics - BiGCaT, Maastricht University, Maastricht, The Netherlands. ${ }^{7}$ German Center for Neurodegenerative Diseases (DZNE), 53127 Bonn, Germany. ${ }^{8}$ Institute of Human Genetics, University of Bonn, 53127 Bonn, Germany. ${ }^{9}$ Department of Genomics, Life \& Brain Center, University of Bonn, 53127 Bonn, Germany. ${ }^{10}$ Division of Medical Genetics, University Hospital and Department of Biomedicine, University of Basel, CH-4058 Basel, Switzerland. ${ }^{11}$ Institute of Social Medicine, Occupational Health and Public Health University of Leipzig, 04103 Leipzig, Germany. ${ }^{12}$ Department of Psychiatry and Psychotherapy, University of Cologne, Medical Faculty, 50937 Cologne, Germany. ${ }^{13}$ Department of Psychiatry and Division of Medical Psychology, University of Bonn, 53105 Bonn, Germany. ${ }^{14}$ Luxembourg Centre for Systems Biomedicine (LCSB), University of Luxembourg, Esch-sur-Alzette, Luxembourg. ${ }^{15}$ Moscow Institute of Physics and Technology, Dolgoprudny, Moscow, Russian Federation. ${ }^{16} \mathrm{ClC}$ bioGUNE, Bizkaia Technology Park, 801 Building, 48160 Derio, Spain. ${ }^{17}$ IKERBASQUE, Basque Foundation for Science, Dolgoprudny Bilbao, Spain. ${ }^{18}$ L.J. Roberts Center for Alzheimer's Research Banner Sun Health Research Institute, Sun City, AZ, USA. ${ }^{19}$ Biodesign Institute, Neurodegenerative Disease Research Center, Arizona State University, Tempe, AZ, USA. ${ }^{20}$ Institute of Psychiatry, King's College London, London, UK. ${ }^{21}$ Department of Psychiatry, Psychosomatics and Psychotherapy, University of Würzburg, Würzburg, Germany.

Received: 8 April 2019 Accepted: 26 September 2019 Published online: 27 November 2019

\section{References}

1. Lambert J-C, Ibrahim-Verbaas CA, Harold D, Naj AC, Sims R, Bellenguez C, et al. Meta-analysis of 74,046 individuals identifies 11 new susceptibility loci for Alzheimer's disease. Nat Genet. Nature Res. 2013;45:1452-8.
2. Lardenoije R, latrou A, Kenis G, Kompotis K, Steinbusch HWM, Mastroeni D, et al. The epigenetics of aging and neurodegeneration. Prog Neurobiol. 2015;131.

3. Lunnon K, Smith R, Hannon E, De Jager PL, Srivastava G, Volta M, et al. Methylomic profiling implicates cortical deregulation of ANK1 in Alzheimer's disease. Nat Neurosci [Internet]. Nature Research; 2014 [cited 2017 Feb 20];17: 1164-1170. Available from: http://www.nature.com/doifinder/10.1038/nn.3782

4. De Jager PL, Srivastava G, Lunnon K, Burgess J, Schalkwyk LC, Yu L, et al. Alzheimer's disease: early alterations in brain DNA methylation at ANK1, BIN1, RHBDF2 and other loci. Nat Neurosci [Internet]. 2014 [cited 2017 Feb 20];17: 1156-1163. Available from: http://www.ncbi.nlm.nih.gov/pubmed/25129075

5. Chouliaras L, Mastroeni D, Delvaux E, Grover A, Kenis G, Hof PR, et al. Consistent decrease in global DNA methylation and hydroxymethylation in the hippocampus of Alzheimer's disease patients. Neurobiol Aging [Internet]. 2013 [cited 2017 Feb 20];34:2091-2099. Available from: http:// www.ncbi.nlm.nih.gov/pubmed/23582657

6. Zhao J, Zhu Y, Yang J, Li L, Wu H, De Jager PL, et al. A genome-wide profiling of brain DNA hydroxymethylation in Alzheimer's disease. Alzheimer's Dement. 2017;13(6):674-88.

7. Kriaucionis $\mathrm{S}$, Heintz $\mathrm{N}$. The nuclear DNA base 5-hydroxymethylcytosine is present in Purkinje neurons and the brain. Science (80- ). 2009;324:929-30 Available from: http://www.pubmedcentral.nih.gov/articlerender.fcgi?artid = 3263819\&tool $=$ pmcentrez\&rendertype $=$ abstract.

8. Nestor CE, Ottaviano R, Reddington J, Sproul D, Reinhardt D, Dunican D, et al. Tissue type is a major modifier of the 5-hydroxymethylcytosine content of human genes. Genome Res [Internet]. Cold Spring Harbor Laboratory Press; 2012 [cited 2017 Oct 31];22:467-477. Available from: http://www.ncbi.nlm.nih.gov/pubmed/22106369

9. Irier H, Street RC, Dave R, Lin L, Cai C, Davis TH, et al. Environmental enrichment modulates 5-hydroxymethylcytosine dynamics in hippocampus. Genomics [Internet]. Academic Press; 2014 [cited 2018 May 14];104:376-382. Available from: https:/www.sciencedirect.com/science/article/pii/S088875431400161X

10. Chen R, Zhang Q, Duan X, York P, Chen G-D, Yin P, et al. The 5Hydroxymethylcytosine ( $5 \mathrm{hmC}$ ) Reader UHRF2 is Required for Normal Levels of $5 \mathrm{hmC}$ in Mouse Adult Brain and Spatial Learning and Memory. J Biol Chem [Internet]. 2017 [cited 2018 May 14];292:4533-4543. Available from: http://www.ncbi.nlm.nih.gov/pubmed/28115522

11. Di Francesco A, Arosio B, Falconi A, Micioni Di Bonaventura MV, Karimi M, Mari D, et al. Global changes in DNA methylation in Alzheimer's disease peripheral blood mononuclear cells. Brain Behav Immun [Internet]. 2015 [cited 2017 Apr 18];45: 139-144. Available from: http//www.ncbi.nlm.nih.gov/pubmed/25452147

12. Li H, Guo Z, Guo Y, Li M, Yan H, Cheng J, et al. Common DNA methylation alterations of Alzheimer's disease and aging in peripheral whole blood. Oncotarget [Internet]. Impact Journals, LLC; 2016 [cited 2017 Apr 30];7:1908919098. Available from: http://www.ncbi.nlm.nih.gov/pubmed/26943045

13. St-Amour I, Cicchetti F, Calon F. Immunotherapies in Alzheimer's disease: Too much, too little, too late or off-target? Acta Neuropathol [Internet]. Springer Berlin Heidelberg; 2016 [cited 2017 29];131:481-504. Available from: http://link.springer.com/10.1007/s00401-015-1518-9

14. Sperling R, Mormino E, Johnson K. The Evolution of Preclinical Alzheimer's Disease: Implications for Prevention Trials. Neuron [Internet]. 2014 [cited 2017 Apr 29];84:608-622. Available from: http://www.ncbi.nlm.nih.gov/ pubmed/25442939

15. Smith AR, Smith RG, Pishva E, Hannon E, Roubroeks JAY, Burrage J, et al. Parallel profiling of DNA methylation and hydroxymethylation highlights neuropathology-associated epigenetic variation in Alzheimer's disease. Clin Epigenetics [Internet]. BioMed Central; 2019 [cited 2019 Sep 9];1:52. Available from: https://clinicalepigeneticsjournal.biomedcentral.com/ articles/10.1186/s13148-019-0636-y

16. Beach TG, Adler CH, Sue LI, Serrano G, Shill HA, Walker DG, et al. Arizona Study of Aging and Neurodegenerative Disorders and Brain and Body Donation Program. Neuropathology [Internet]. 2015 [cited 2017 Nov 22];35: 354-389. Available from: http://www.ncbi.nlm.nih.gov/pubmed/25619230

17. Ray M, Zhang W, Liang W, Dunckley T, Beach T, Grover A, et al. Analysis of Alzheimer's disease severity across brain regions by topological analysis of gene co-expression networks. BMC Syst Biol. BioMed Central; 2010;4:136.

18. Coppieters N, Dieriks B V, Lill C, Faull RL, Curtis MA, Dragunow M. Global changes in DNA methylation and hydroxymethylation in Alzheimer's disease human brain. Neurobiol Aging [Internet]. 2014;35:1334-1344. Available from: http://www.ncbi.nlm.nih.gov/pubmed/24387984

19. Piras IS, Krate J, Delvaux E, Nolz J, Mastroeni DF, Persico AM, et al. Transcriptome Changes in the Alzheimer's Disease Middle Temporal Gyrus: 
Importance of RNA Metabolism and Mitochondria-Associated Membrane Genes. Combs C, editor. J Alzheimer's Dis [Internet]. 2019 [cited 2019 Sep 9]; 70:691-713. Available from: http://www.ncbi.nlm.nih.gov/pubmed/31256118

20. Kamkwalala A, Newhouse P. Beyond Acetylcholinesterase Inhibitors: Novel Cholinergic Treatments for Alzheimer's Disease. Curr Alzheimer Res [Internet]. 2016 [cited 2017 Dec 10];13:1. Available from: http://www.ncbi. nlm.nih.gov/pubmed/27697062

21. Adrain C, Zettl M, Christova Y, Taylor N, Freeman M. Tumor Necrosis Factor Signaling Requires iRhom2 to Promote Trafficking and Activation of TACE. Sci Reports. 2012;335:225-8.

22. Bhaskar K, Maphis N, Xu G, Varvel NH, Kokiko-Cochran ON, Weick JP, et al. Microglial derived tumor necrosis factor-a drives Alzheimer's disease-related neuronal cell cycle events. Neurobiol Dis [Internet]. 2014 [cited 2018 Jun 20];62: 273-285. Available from: http://www.ncbi.nlm.nih.gov/pubmed/24141019

23. Zhang K, Programs F, Boe C, Barbieri M, Crimmins EM, Preston SH, et al. Complement and microglia mediate early synapse loss in Alzheimer mouse models. Science. 2016;352(6286):712-6.

24. Meerabux JMA, Ohba H, Iwayama Y, Maekawa M, Detera-Wadleigh SD, DeLisi LE, et al. Analysis of a t(18;21)(p11.1;p11.1) translocation in a family with schizophrenia. J Hum Genet [Internet]. 2009 [cited 2018 May 22];54: 386-391. Available from: http://www.ncbi.nlm.nih.gov/pubmed/19461657

25. Kikuchi M, Yamada K, Toyota T, Yoshikawa T. C18orf1 located on chromosome 18p11.2 may confer susceptibility to schizophrenia. J Med Dent Sci [Internet]. 2003 [cited 2018 May 22];50:225-229. Available from: http://www.ncbi.nlm.nih.gov/pubmed/15074360

26. Nakano N, Maeyama K, Sakata N, Itoh F, Akatsu R, Nakata M, et al. C18 ORF1, a novel negative regulator of transforming growth factor- $\beta$ Signaling. J Biol Chem [Internet]. 2014 [cited 2018 May 22];289:12680-12692. Available from: http://www.ncbi.nlm.nih.gov/pubmed/24627487

27. Lew D, Ehret GB, Rice K Verwoert GC, Launer $\sqcup$, Dehghan A, et al. Genome-wide association study of blood pressure and hypertension. Nat Genet [internet]. 2009 [cited 2018 May 22];41:677-687. Available from: http//wnww.ncbi.nlm.nih.gov/pubmed/19430479

28. Chong JR, Chai YL, Lee JH, Howlett D, Attems J, Ballard CG, et al. Increased transforming growth factor $\beta 2$ in the neocortex of Alzheimer's disease and dementia with Lewy bodies is correlated with disease severity and soluble Aß42 load. J Alzheimer's Dis [Internet]. 2017 [cited 2018 May 22];56:157-166. Available from: http://www.ncbi.nlm.nih.gov/pubmed/27911312

29. Young TR, Leamey CA. Teneurins: Important regulators of neural circuitry. Int J Biochem Cell Biol [Internet]. 2009 [cited 2018 May 22];41:990-993. Available from: http://www.ncbi.nlm.nih.gov/pubmed/18723111

30. Bai Z, Stamova B, Xu H, Ander BP, Wang J, Jickling GC, et al. Distinctive RNA expression profiles in blood associated with Alzheimer disease after accounting for white matter hyperintensities. Alzheimer Dis Assoc Disord [Internet]. NIH Public Access; 2014 [cited 2018 May 22];28:226-233. Available from: http://www.ncbi.n/m.nih.gov/pubmed/24731980

31. Yao C, Joehanes R, Johnson AD, Huan T, Esko T, Ying S, et al. Sex- and ageinteracting eQTLs in human complex diseases. Hum Mol Genet [Internet]. Oxford University Press; 2014 [cited 2018 May 22];23:1947-1956. Available from: https:/academic.oup.com/hmg/article-lookup/doi/10.1093/hmg/ddt582

32. P Bennett J, M Keeney P. Micro RNA's (mirna's) may help explain expression of multiple genes in Alzheimer's Frontal Cortex. J Syst Integr Neurosci [Internet]. 2017 [cited 2018 May 22];3. Available from: http://www.oatext.com/micro-rnas-mirnasmay-help-explain-expression-of-multiple-genes-in-alzheimers-frontal-cortex.php

33. Tian $Y$, Bustos $V$, Flajolet $M$, Greengard P. A small-molecule enhancer of autophagy decreases levels of Abeta and APP-CTF via Atg5-dependent autophagy pathway. FASEB J [Internet]. The Federation of American Societies for Experimental Biology; 2011 [cited 2018 May 22];25:1934-42. Available from: http://www.ncbi.nlm.nih.gov/pubmed/21368103

34. Khrimian L, Obri A, Karsenty G. Modulation of cognition and anxiety-like behavior by bone remodeling. Mol Metab [Internet]. Elsevier; 2017 [cited 2018 May 22];6:1610-1615. Available from: https://www.sciencedirect.com/ science/article/pii/S2212877817306877

35. Gibbs GM, Roelants K, O'Bryan MK. The CAP superfamily: cysteine-rich secretory proteins, antigen 5, and pathogenesis-related 1 proteins-roles in reproduction, cancer, and immune defense. Endocr Rev [Internet]. Oxford University Press; 2008 [cited 2018 May 22];29:865-897. Available from: https://academic.oup.com/edrv/article-lookup/doi/10.1210/er.2008-0032

36. Ren C, Ren C-H, Li L, Goltsov AA, Thompson TC. Identification and characterization of RTVP1/GLIPR1-like genes, a novel p53 target gene cluster. Genomics [Internet]. 2006 [cited 2018 May 22];88:163-172. Available from: http://www.ncbi.n/m.nih.gov/pubmed/16714093
37. Song L, Pei L, Yao S, Wu Y, Shang Y. NLRP3 inflammasome in neurological diseases, from functions to therapies. Front Cell Neurosci [Internet]. Frontiers; 2017 [cited 2018 May 22];11:63. Available from: http://journal. frontiersin.org/article/10.3389/fncel.2017.00063/full

38. Tan M-S, Tan L, Jiang T, Zhu X-C, Wang H-F, Jia C-D, et al. Amyloid- $\beta$ induces NLRP1-dependent neuronal pyroptosis in models of Alzheimer's disease. Cell Death Dis [Internet]. 2014 [cited 2018 May 22];5:e1382. Available from: http://www.ncbi.n/m.nih.gov/pubmed/25144717

39. Gusareva ES, Carrasquillo MM, Bellenguez C, Cuyvers E, Colon S, Graff-Radford $\mathrm{NR}$, et al. Genome-wide association interaction analysis for Alzheimer's disease. Neurobiol Aging [Internet]. NIH Public Access; 2014 [cited 2017 Nov 15];35: 2436-2443. Available from: http://www.ncbi.nlm.nih.gov/pubmed/24958192

40. Fatima SS, Rehman R, Baig M, Khan TA. New roles of the multidimensional adipokine: Chemerin. Peptides [Internet]. Elsevier; 2014 [cited 2018 May 23];62:15-20. Available from: https:/umw.sciencedirect.com/science/article/abs/pii/S01969781 14002885

41. Gasparoni G, Bultmann S, Lutsik P, Kraus TFJ, Sordon S, Vlcek J, et al. DNA methylation analysis on purified neurons and glia dissects age and Alzheimer's disease-specific changes in the human cortex. Epigenetics Chromatin [Internet]. 2018 [cited 2019 Jun 24];1:41. Available from: http//wuww.ncbi.nlm.nih.gov/pubmed/30045751

42. McGeer PL, McGeer EG. The amyloid cascade-inflammatory hypothesis of Alzheimer disease: implications for therapy. Acta Neuropathol [Internet]. Springer Berlin Heidelberg; 2013 [cited 2019 Mar 22];126:479-497. Available from: http://link.springer.com/10.1007/s00401-013-1177-7

43. Watson CT, Roussos P, Garg P, Ho DJ, Azam N, Katsel PL, et al. Genome-wide DNA methylation profiling in the superior temporal gyrus reveals epigenetic signatures associated with Alzheimer's disease. Genome Med [Internet]. BioMed Central; 2016 [cited 2017 Apr 30],8:5. Available from: http//wnw.ncbi.nlm.nih.gov/pubmed/26803900

44. Olff M, Frijling JL, Kubzansky LD, Bradley B, Ellenbogen MA, Cardoso C, et al. The role of oxytocin in social bonding, stress regulation and mental health: An update on the moderating effects of context and interindividual differences. Psychoneuroendocrinology. 2013;38:1883-94.

45. Haas BW, Filkowski MM, Cochran RN, Denison L, Ishak A, Nishitani S, et al. Epigenetic modification of OXT and human sociability. Proc Natl Acad Sci U S A [Internet]. National Academy of Sciences; 2016 [cited 2018 Jun 22];113: E3816-E3823. Available from: http://www.ncbi.nlm.nih.gov/pubmed/27325757

46. Swaab DF, Chapter II. Neurobiology and neuropathology of the human hypothalamus. Handb Chem Neuroanat. Elsevier. 1997;13:39-137.

47. de Lacalle S, Iraizoz I, Gonzalo LM. Cell loss in supraoptic and paraventricular nucleus in Alzheimer's disease. Brain Res [Internet]. 1993 [cited 2018 May 14]; 609:154-158. Available from: http://www.ncbi.nlm.nih.gov/pubmed/8508299

48. Mazurek MF, Beal MF, Bird ED, Martin JB. Oxytocin in Alzheimer's disease: postmortem brain levels. Neurology [Internet]. 1987 [cited 2018 May 14];37: 1001-1003. Available from: http://www.ncbi.nlm.nih.gov/pubmed/3587615

49. North WG, Harbaugh R, Reeder T. An evaluation of human neurophysin production in Alzheimer's disease: preliminary observations. Neurobiol Aging [Internet]. 1992 [cited 2018 May 14];13:261-265. Available from: http://www.ncbi.nlm.nih.gov/pubmed/1522943

50. Mann DM, Yates PO, Marcyniuk B. Changes in Alzheimer's disease in the magnocellular neurones of the supraoptic and paraventricular nuclei of the hypothalamus and their relationship to the noradrenergic deficit. Clin Neuropathol [Internet]. 1985 [cited 2018 May 14];4:127-134. Available from: http://www.ncbi.nlm.nih.gov/pubmed/3160517

51. Torner L, Plotsky PM, Neumann ID, de Jong TR. Forced swimming-induced oxytocin release into blood and brain: Effects of adrenalectomy and corticosterone treatment. Psychoneuroendocrinology [Internet]. 2017 [cited 2017 Jul 6];77:165-174. Available from: http//linkinghub.elsevier.com/retrieve/pii/S0306453016306801

52. Tampi RR, Maksimowski M, Ahmed M, Tampi DJ. Oxytocin for frontotemporal dementia: a systematic review. Ther Adv Psychopharmacol [Internet]. SAGE PublicationsSage UK: London, England; 2017 [cited 2017 Dec 10];7:48-53. Available from: http://journals.sagepub.com/doi/10.1177/2045125316672574

53. Lunnon K, Mill J. Epigenetic studies in Alzheimer's disease: current findings, caveats, and considerations for future studies. Am J Med Genet B Neuropsychiatr Genet [Internet]. 2013 [cited 2015 Dec 7];162B:789-799. Available from: http://www.pubmedcentral.nih.gov/articlerender.fcgi?artid = 3947441\&tool = pmcentrez\&rendertype $=$ abstract

54. Beach TG, Sue LI, Walker DG, Roher AE, Lue L, Vedders $L$, et al. The Sun Health Research Institute Brain Donation Program: Description and Eexperience, 1987-2007. Cell Tissue Bank. Springer Netherlands; 2008;9:229-245.

55. Luck T, Riedel-Heller SG, Kaduszkiewicz H, Bickel H, Jessen F, Pentzek M, et al. Mild cognitive impairment in general practice: age-specific prevalence and correlate results from the German study on ageing, cognition and 
dementia in primary care patients (AgeCoDe). Dement Geriatr Cogn Disord [Internet]. 2007 [cited 2017 Nov 22];24:307-316. Available from: https:// www.karger.com/Article/FullText/108099

56. Ramirez A, Wolfsgruber S, Lange C, Kaduszkiewicz H, Weyerer S, Werle J, et al. Elevated $\mathrm{HbA1c}$ is associated with increased risk of incident dementia in primary care patients. J Alzheimers Dis [Internet]. 2015 [cited 2017 Nov 22];44: 1203-1212. Available from: http:/www.ncbi.n/m.nih.gov/pubmed/25524954

57. Zaudig M, Hiller W. Sidam-Handbuch. Strukturiertes Interview für die Diagnose einer Demenz vom Alzheimer Typ, der Multi-Infarkt-(oder vaskulären) Demenzen und Demenzen anderer Ätiologien nach DSM-III-R, DSM-IV und ICD-10. Bern: Huber; 1996.

58. Reisberg B, Ferris SH, de Leon MJ, Crook T. The Global Deterioration Scale for assessment of primary degenerative dementia. Am J Psychiatry [Internet]. 1982 [cited 2017 Apr 20];139:1136-1139. Available from: http:// www.ncbi.nlm.nih.gov/pubmed/7114305

59. McKhann G, Drachman D, Folstein M, Katzman R, Price D, Stadlan EM. Clinical diagnosis of Alzheimer's disease: report of the NINCDS-ADRDA Work Group under the auspices of Department of Health and Human Services Task Force on Alzheimer's Disease. Neurology [Internet]. 1984 [cited 2017 Apr 20];34:939944. Available from: http://www.ncbi.nlm.nih.gov/pubmed/6610841

60. R Core Team. R: A language and environment for statistical computing. [Internet]. Vienna, Austria: R Foundation for Statistical Computing; 2016. Available from: https://www.r-project.org/

61. RStudio Team. RStudio: Integrated Development for R [Internet]. Boston, MA: RStudio, Inc.; 2016. Available from: http://www.rstudio.com/

62. Aryee MJ, Jaffe AE, Corrada-Bravo H, Ladd-Acosta C, Feinberg AP, Hansen $K D$, et al. Minfi: a flexible and comprehensive Bioconductor package for the analysis of Infinium DNA methylation microarrays. Bioinformatics. Oxford University Press; 2014;30:1363-1369.

63. Heiss JA, Just AC. Identifying mislabeled and contaminated DNA methylation microarray data: an extended quality control toolset with examples from GEO. Clin Epigenetics [Internet]. BioMed Central; 2018 [cited 2019 Jun 24];10:73. Available from: http://www.ncbi.nlm.nih.gov/pubmed/29881472

64. van Iterson M, Tobi E, Slieker R, den Hollander, Wouter Luijk R, Dekkers K, Heijmans B. DNAmArray [Internet]. Leiden, the Netherlands; 2017. Available from: https://github.com/molepi/DNAmArray

65. Chen Y, Lemire M, Choufani S, Butcher DT, Grafodatskaya D, Zanke BW, et al. Discovery of cross-reactive probes and polymorphic CpGs in the Illumina Infinium HumanMethylation450 microarray. Epigenetics. Taylor \& Francis. 2013;8:203-9.

66. Pidsley R, YW CC, Volta M, Lunnon K, Mill J, Schalkwyk LC. A data-driven approach to preprocessing Illumina $450 \mathrm{~K}$ methylation array data. BMC Genomics. 2013;14:293.

67. Fukuzawa S, Takahashi S, Tachibana K, Tajima S, Suetake I. Simple and accurate single base resolution analysis of 5-hydroxymethylcytosine by catalytic oxidative bisulfite sequencing using micelle incarcerated oxidants. Bioorg Med Chem. 2016;24:4254-62.

68. Song C-X, He C. Potential functional roles of DNA demethylation intermediates. Trends Biochem Sci. 2013;38:480-4.

69. Leek JT, Johnson WE, Parker HS, Jaffe AE, Storey JD. The sva package for removing batch effects and other unwanted variation in high-throughput experiments. Bioinformatics [nternet]. Oxford University Press; 2012 [cited 2017 Apr 10];28:882883. Available from: http///uww.ncbinlm.nih.gov/pubmed/22257669

70. Ritchie ME, Phipson B, Wu D, Hu Y, Law CW, Shi W, et al. limma powers differential expression analyses for RNA-sequencing and microarray studies. Nucleic Acids Res [Internet]. 2015 [cited 2017 Apr 10];43:e47. Available from: https://academic.oup.com/nar/article-lookup/doi/10.1093/nar/gkv007

71. van Iterson M, van Zwet EW, BIOS Consortium BT, Heijmans BT. Controlling bias and inflation in epigenome- and transcriptome-wide association studies using the empirical null distribution. Genome Biol [Internet]. 2017 [cited 2017 Apr 10];18:19. Available from: http://genomebiology. biomedcentral.com/articles/10.1186/s13059-016-1131-9

72. Slieker RC, Bos SD, Goeman JJ, Bovée JV, Talens RP, van der Breggen R, et al. Identification and systematic annotation of tissue-specific differentially methylated regions using the Illumina 450k array. Epigenetics Chromatin. BioMed Central; 2013;6:26.

73. Pedersen BS, Schwartz DA, Yang IV, Kechris KJ. Comb-p: software for combining, analyzing, grouping and correcting spatially correlated P-values. Bioinformatics. Oxford University Press. 2012;28:2986-8.

74. Schadt EE, Friend SH, Shaywitz DA. A network view of disease and compound screening. Nat Rev Drug Discov [Internet]. 2009 [cited 2017 Dec 6];8:286-295. Available from: http://www.ncbi.nlm.nih.gov/pubmed/19337271
75. Jonsson PF, Bates PA. Global topological features of cancer proteins in the human interactome. Bioinformatics [Internet]. 2006 [cited 2017 Dec 6];22: 2291-2297. Available from: http://www.ncbi.nlm.nih.gov/pubmed/16844706

76. Barabási A-L, Gulbahce N, Loscalzo J. Network medicine: a network-based approach to human disease. Nat Rev Genet [Internet]. 2011 [cited 2017 Dec 6];12:56-68. Available from: http://www.ncbi.nlm.nih.gov/pubmed/21164525

77. Zickenrott S, Angarica VE, Upadhyaya BB, del Sol A. Prediction of diseasegene-drug relationships following a differential network analysis. Cell Death Dis [Internet]. 2016 [cited 2017 Dec 5];7:e2040. Available from: http://www. nature.com/doifinder/10.1038/cddis.2015.393

78. Nikitin A, Egorov S, Daraselia N, Mazo I. Pathway studio-the analysis and navigation of molecular networks. Bioinformatics [Internet]. 2003 [cited 2017 Dec 6];19:21552157. Available from: http://www.ncbi.nlm.nih.gov/pubmed/14594725

79. Plahte E, Mestl T, Omholt SW. Feedback loops, stability and multistationarity in dynamical systems. J Biol Syst [Internet]. World Scientific Publishing Company; 1995 [cited 2017 Dec 6];03:409-413. Available from: http://www. worldscientific.com/doi/abs/10.1142/S0218339095000381

80. Thomas R. On the relation between the logical structure of systems and their ability to generate multiple steady states or sustained oscillations. Springer, Berlin, Heidelberg; 1981 [cited 2017 Dec 6]. p. 180-93. Available from: http://link.springer.com/10.1007/978-3-642-81703-8_24

81. Harrell Jr FE, with contributions from Charles Dupont and many others. Hmisc: Harrell Miscellaneous. R package version 4.0-3 [Internet]. 2017. Available from: https://cran.r-project.org/package $=$ Hmisc

\section{Publisher's Note}

Springer Nature remains neutral with regard to jurisdictional claims in published maps and institutional affiliations.

Ready to submit your research? Choose BMC and benefit from:

- fast, convenient online submission

- thorough peer review by experienced researchers in your field

- rapid publication on acceptance

- support for research data, including large and complex data types

- gold Open Access which fosters wider collaboration and increased citations

- maximum visibility for your research: over $100 \mathrm{M}$ website views per year

At $\mathrm{BMC}$, research is always in progress.

Learn more biomedcentral.com/submissions 